Utah State University

DigitalCommons@USU

$1-1-2001$

\title{
Initial Observations of Mesospheric Winds Using IDI Radar Measurements at the Bear Lake Observatory
}

\author{
F. T. Berkey \\ Utah State University \\ C. S. Fish \\ Utah State University
}

Follow this and additional works at: https://digitalcommons.usu.edu/sdl_pubs

\section{Recommended Citation}

Berkey, F. T. and Fish, C. S., "Initial Observations of Mesospheric Winds Using IDI Radar Measurements at the Bear Lake Observatory" (2001). Space Dynamics Lab Publications. Paper 14.

https://digitalcommons.usu.edu/sdl_pubs/14

This Article is brought to you for free and open access by the Space Dynamics Lab at DigitalCommons@USU. It has been accepted for inclusion in Space Dynamics Lab Publications by an authorized administrator of DigitalCommons@USU. For more information, please contact digitalcommons@usu.edu.

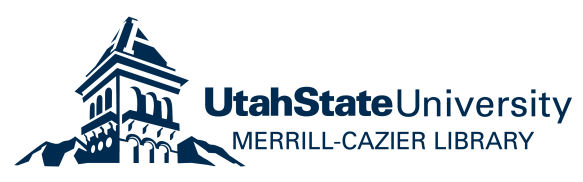




\title{
Initial Observations of Mesospheric Winds Using IDI Radar Measurements at the Bear Lake Observatory
}

\author{
F.T. Berkey and C.S. Fish \\ Utah State University, Logan, Utah
}

G.O.L. Jones

British Antarctic Survey, Cambridge, UK

\begin{abstract}
The adaptation of Imaging Doppler Interferometry (IDI) to the dynasonde deployed at the Bear Lake Observatory $\left(41.9^{\circ} \mathrm{N}, 111.4^{\circ} \mathrm{W}\right)$ in northeastern Utah enables the routine measurement of mesospheric dynamics. Influenced by the direction of the prevailing wind, a clear seasonal variation is seen in the mesospheric echo numbers. The technique also provides a monitor for the amplitude of the main tidal modes as well as for studying planetary waves with periods of several days. The observations are found to be consistent with those from different instruments based at the same site thus confirming the IDI characterisation of the mesospheric wind field.
\end{abstract}

\section{Introduction}

The IDI technique was conceived at Utah State University (USU) by Adams and co-workers and further developed using a NOAA dynasonde [Grubb, 1979; Adams et al., $1985,1986]$. Initially implemented only on a campaign basis [Brosnahan and Adams, 1993; Turek et al., 1995], these early results enabled the efficacy of the IDI technique to be studied by the radar community [Roper, 1998 and references therein].

In late 1998, the USU dynasonde operational at the Bear Lake Observatory was configured to acquire IDI soundings and regular synoptic measurements were begun in February 1999. This implementation of IDI followed successful observations conducted by the British Antarctic Survey at their Halley $\left(76^{\circ} \mathrm{S}, 26^{\circ} \mathrm{W}\right)$ research station [Jones et al., 1997]. Routine IDI soundings at Halley have been interleaved with ionograms since 1997 and, based on the first full year of mesospheric measurements [Charles and Jones, 1999], it was concluded that IDI is a viable technique for observing the structure and dynamics of the mesospheric wind field at heights from $70-105 \mathrm{~km}$, a result also supported by this paper.

\section{Mesospheric Dynamics Derived from Bear Lake IDI Measurements}

The results to be discussed here have been derived from IDI data collected at the Bear Lake Observatory over a 14 month interval extending through April 2000. IDI soundings are carried out at a fixed frequency in the upper MF or

Copyright 2001 by the American Geophysical Union.

Paper number 2000 GL011854.

0094-8276/01/2000GL011854\$05.00 lower HF portions of the radio spectrum. As implemented at the Bear Lake Observatory, the soundings are made at $2.2 \mathrm{MHz}$ during nighttime (00-13 UT) and $3.8 \mathrm{MHz}$ during the remainder of the day over the height range from 50 to $115 \mathrm{~km}$. These soundings are acquired at 5-min intervals utilizing a schedule identical to that employed at Halley.

One of the benchmarks used to quantify the IDI sounding scheme has been the determination of the number of "echoes" per sounding as derived from averaging this value over all of the soundings acquired for any given UT day. Typically, IDI echoes are detected at Bear Lake over heights extending from 70-115 km, although echoes from lower heights are frequently recorded during the day. At $\mathrm{Hal}-$ ley, where 3 years of data have now been acquired, the echo number varies in a systematic manner and maxima ( $\approx 600-800 /$ sounding) are found to occur during the austral winter and summer months with pronounced minima $(\approx 50$ 100 /sounding) during spring and fall.

The initial results from Bear Lake were unanticipated in that often 2-3 times the number of echoes/sounding observed at Halley were detected (see Fig. 1). This trend proved to be consistent throughout the year and a peak of $\approx 4500$ echoes/sounding was recorded in January. The maxima tended to occur when the zonal wind was strongly westward at heights $>80 \mathrm{~km}$ and the greatest number of echoes was observed when a strong westward zonal wind extended over the range from $60-100 \mathrm{~km}$. Minima $(\approx 900$ echoes/sounding) were recorded in April, August and for a short duration in January, corresponding to intervals when the mean zonal winds were eastward.

\section{Mean Winds}

Using a ten-day running mean, the meridional and zonal mean winds have been derived from the Bear Lake IDI measurements over heights between 60 and $110 \mathrm{~km}$. As shown in Fig. 2 (top panel), the meridional wind is predominantly equatorward, reaching a mean velocity of $\approx 20 \mathrm{~ms}^{-1}$. These winds are punctuated, especially during the mid-winter and early spring intervals, by intervals of northward wind which are generally confined to $\mathrm{h}>90 \mathrm{~km}$ and attain velocities up to $\approx 15 \mathrm{~ms}^{-1}$. The zonal winds are strongly westward at all heights during the late spring and early summer months reaching velocities of $25 \mathrm{~ms}^{-1}$. A marked change occurred during August and September when eastward winds dominated at heights $>85 \mathrm{~km}$. During the winter months a westward wind prevailed, particularly below $95 \mathrm{~km}$, although intervals dominated by eastward winds were observed at heights $>85 \mathrm{~km}$ after mid-January. 


\section{Spectral Analysis}

To extract the tidal and planetary wave features, the data were subjected to spectral analysis, although only those data for the $95-100 \mathrm{~km}$ height window are shown here (Fig. 3). These spectra were derived by taking 43-days of hourly mean wind values and calculating a sliding periodogram every 5 days. The computations utilized a fast Fourier transform which employed a Tukey window to taper the edges of the sampling window. The tidal amplitudes were derived from the application of sine wave fitting to the different periodicities.

For the meridional wind component, the diurnal tide was found to attain a peak magnitude of $\approx 20 \mathrm{~ms}^{-1}$ during spring, while it was much weaker between mid-August and November. Diurnal tidal effects were evident at all heights between $75-110 \mathrm{~km}$, especially in the late winter and early spring months. The semidiurnal tide dominates the diurnal tide over most of the year at heights $>90 \mathrm{~km}$ reaching amplitudes twice that of the diurnal tidal component. The largest amplitude semidiurnal tides were prevalent over the same time that strong zonal (eastward) winds occurred, starting in mid-July and ending in late October. The diurnal tide is predominantly evident in the zonal wind component from late winter through early summer, reaching a magnitude of $\approx 30 \mathrm{~ms}^{-1}$ for $\mathrm{h}>90 \mathrm{~km}$. These tidal amplitudes are consistent with measurements conducted at the same location using an Imaging Fabry-Perot Interferometer to measure the hydroxyl (OH) emission [East et al., 1995].

The meridional and zonal winds also exhibit a terdiurnal tidal component [Smith, 2000], albeit weaker than either the diurnal or semidiurnal tides. This tidal feature was especially evident in the fall of 1999 and the spring of 2000 , coinciding (during 1999) with strong westward zonal winds at heights $<100 \mathrm{~km}$ that attained a magnitude of $\approx 10$ $\mathrm{ms}^{-1}$ at heights between $80-110 \mathrm{~km}$. The zonal component exhibits similar characteristics but tends to have an earlier onset $(\approx 30$ days) than the meridional terdiurnal tide. These results are consistent with recent optical observations of a terdiurnal tide at $\approx 87 \mathrm{~km}$ in the $\mathrm{OH}$ rotational temperature measurements acquired with the USU temperature mapper [Taylor et al., 1999; Pendelton et al., 2000].

\section{Planetary Waves}

An expanded version of Fig. 3 is reproduced as Fig. 4 to allow resolution of the planetary wave periods that are also present in the data. The dotted lines are intended as a guide to identify the various wave periods. The most dominant feature in the meridional wind component at $95-\mathrm{km}$ occurs at $\approx 16$-days and is confined to the fall and winter months. Also evident in the spectrum are waves with periods of 5-6 days and 3.8 days. The zonal wind component at $95 \mathrm{~km}$ exhibits a much richer variety of planetary wave periods. The dominant spectral peak that occurs in January/February 2000 appears to have an even longer period $(\approx 20$ days) and may conceivably arise from a Doppler shift of different wave periods. Spectral peaks at 16, 10, 8.3, 6 and 3.1 days are also suggested by these data. While all of these wave modes are strongest during the winter months, the zonal wind component also exhibits long period waves during the summer. It has been suggested that the summer 16-day waves can result from leakage from the winter hemisphere [Espy et al., 1997]. The results shown here are con- sistent with the study of quasi 16-day oscillations observed in MF radar measurements from Saskatoon $\left(52^{\circ} \mathrm{N}\right)$ during 1980-1996 [Luo et al., 2000]. They regularly observe 16-day waves dominantly in the zonal component and preferentially during eastward mean flow.

A quasi-two-day wave (QTDW) is also commonly detected at middle latitudes with predictable regularity [Harris, 1994]. The QTDW is reported to be mainly a summer phenomenon whose amplitude attains a maximum between 85$95 \mathrm{~km}$ (above Adelaide). The QTDW was also present above Bear Lake in June and July and was most prominent in the meridional wind component between $75-110 \mathrm{~km}$, reaching an amplitude of $15 \mathrm{~ms}^{-1}$. As with the 16-day wave, the zonal wind component exhibited several distinct wave periods, ranging from 1.8 to 2.5 days over this same time interval. The zonal wind exhibited a clear QTDW during December and January with almost no corresponding energy appearing in the meridional wind component.

\section{Discussion}

The seasonal variation of echo numbers is clear and similar at both Bear Lake and Halley but the consistently larger numbers of echoes at $42^{\circ} \mathrm{N}$ warrants some comment. The most obvious differences are the geodetic locations and the geographic settings of the two sites. The radar configurations differ only in detail and would suggest that the Halley system should be more sensitive, due to the utilization of a more efficient transmitting antenna and a generally lower ambient radio background environment. Although crosscalibration between the various dynasondes has not been conducted in a systematic manner, work by [Wright, 1998] suggests that the efficiency of the transmitting antenna is an important parameter. The differences in spacing between receiving elements, as well as the choice of operating fre-
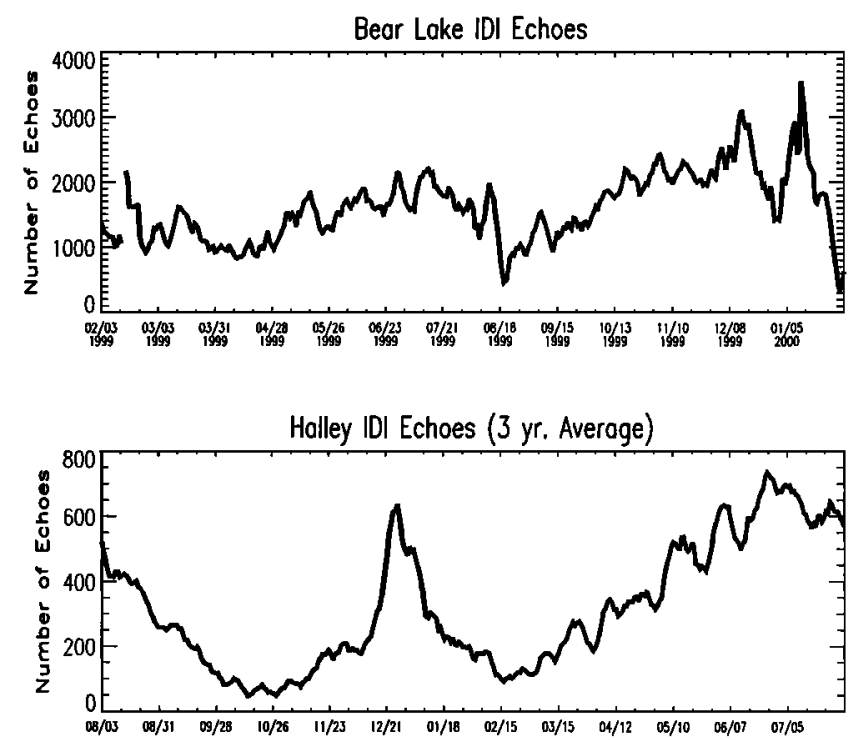

Figure 1. The number of IDI echoes per sounding (averaged over the total number of soundings for each day) recorded at Bear Lake (top panel) and Halley (bottom panel) as a function of day of year. The Halley data have been averaged over a 3 year interval and the data have been smoothed with a filter of 7 days. Note that the vertical axes in the two panels differ and the horizontal axes shifted so that the summer and winter periods at the two sites coincide. 

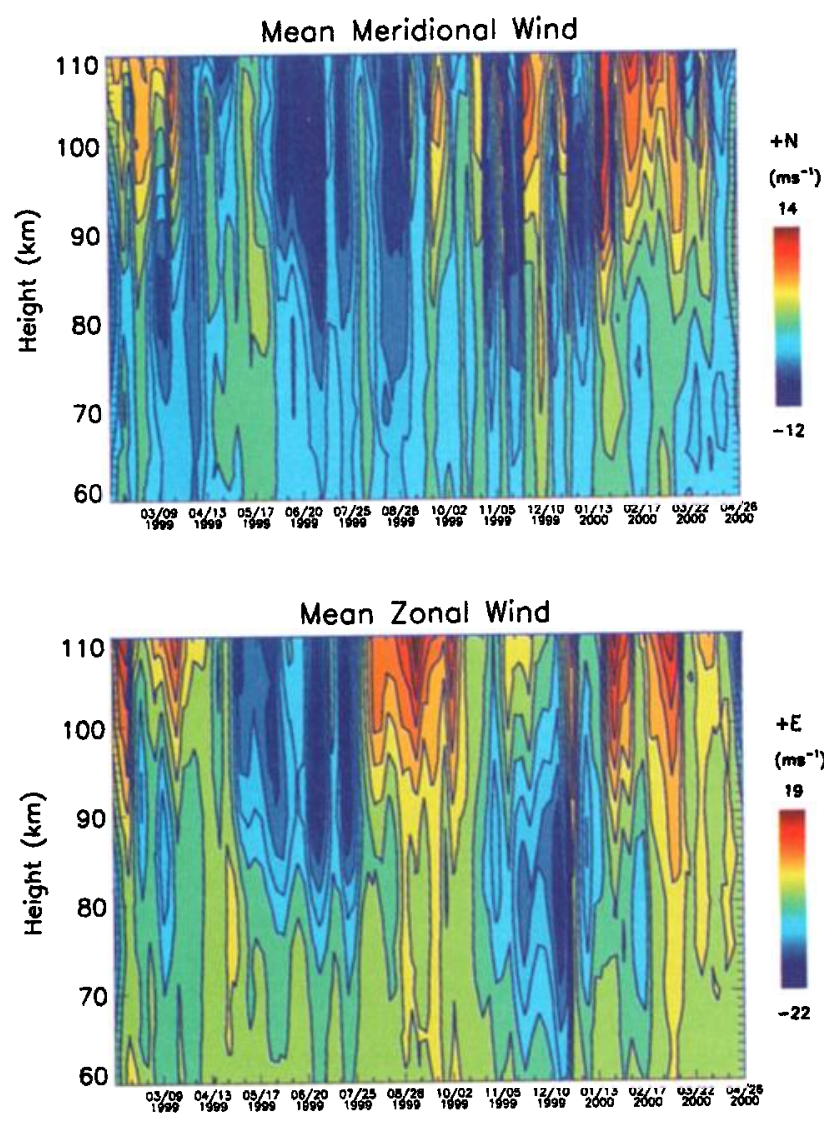

Figure 2. Mean meridional and zonal winds over heights 60-110 $\mathrm{km}$ derived from IDI measurements conducted at the Bear Lake Observatory during 1999 and early 2000.

quency, are additional factors that will be examined in future soundings. However, the most plausible explanations
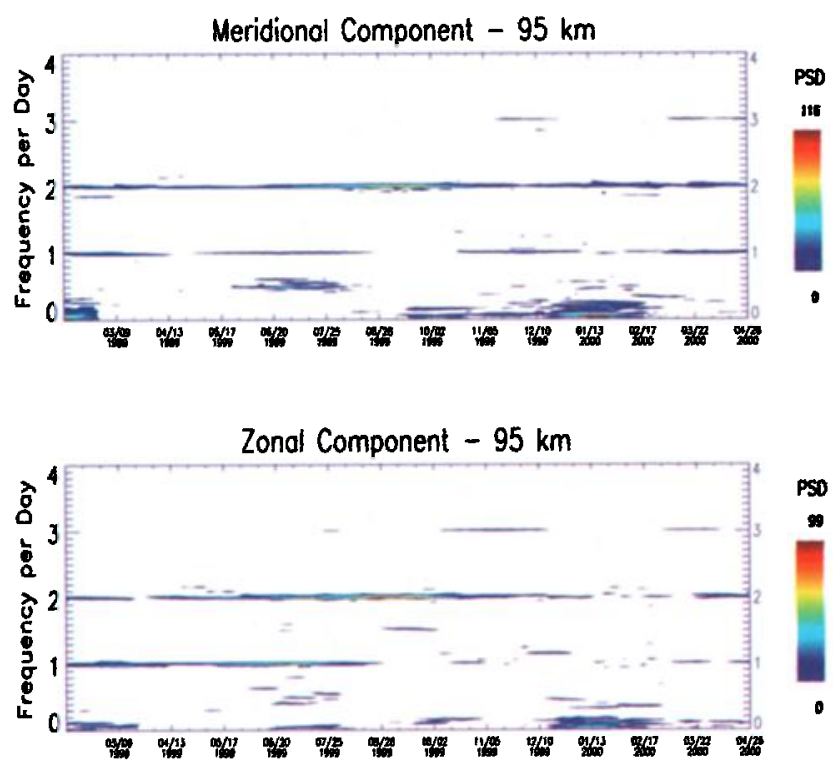

Figure 3. A spectrogram of the meridional (top panel) and zonal components (bottom panel) of the wind field at $95 \mathrm{~km}$ for data obtained between February 1999 and April 2000. The relative spectral density is indicated by color with red denoting high densities.
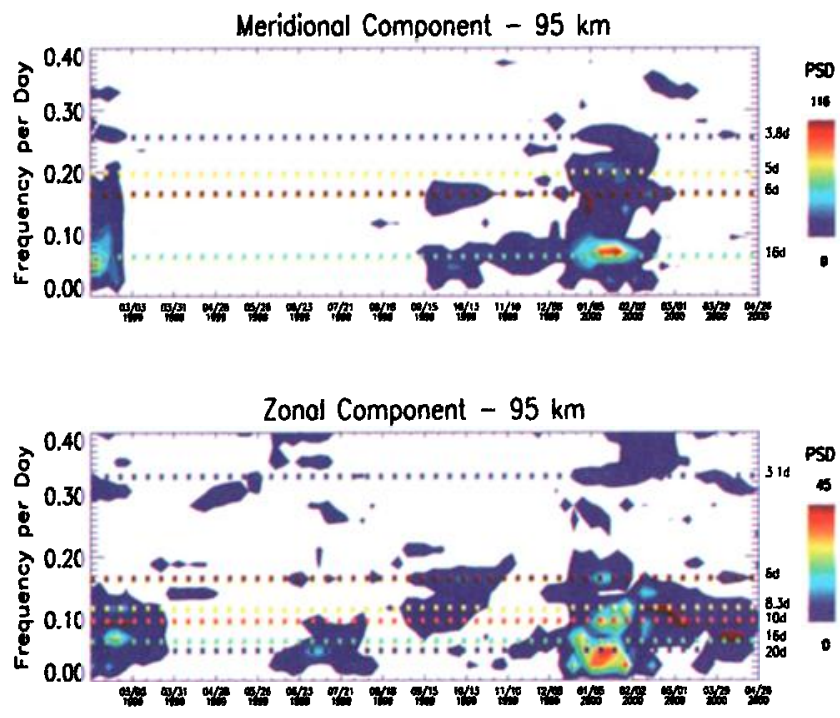

Figure 4. Same as Figure 3 but for frequencies less than $0.4 /$ day. The horizontal dashed and dotted lines indicate various wave periods between 3.1 and 20 days.

for the increased number of echoes at Bear Lake are of geophysical origin.

The spring minimum at Halley has been attributed to the breakdown of the circumpolar vortex over Antarctica and a concomitant reduction of the transport of momentum and energy flux into the mesosphere, leading to a reduction in gravity wave amplitudes and turbulent wave activity [Jones and Jarvis, 1995]. The Bear Lake Observatory is situated such that orographic features could be responsible for generating more prolific wave activity at mesospheric heights. Monochromatic all-sky imaging data suggest that considerable small-scale wave activity is prevalent above Bear Lake[Taylor, personal communication, 2000]. The planned installation of an all-sky imager at Halley will, in the future, allow direct comparison of small-scale wave activity at the two sites.

\section{Summary}

The first year of IDI measurements using the USU dynasonde have revealed the presence of a rich variety of dynamics and structures in the mesosphere above the Bear Lake Observatory. Tidal periods of 8,12 and 24 hour periods are clearly evident in the data throughout the entire dataset. Moreover, the signature of planetary waves with periods between 2-20 days were also a feature of the wave structures observed in the data. Currently, these data are being used to study the morphology of small-scale wave structure in the mesosphere which has been derived from a co-sited all-sky imager. Future work will include a more detailed analysis of these existing data and will incorporate measurements from the USU lidar and temperature mapper.

Acknowledgments. This work has been supported by the Space Dynamics Laboratory, the Rocky Mountain NASA Space Grant Consortium, and grants OPP95-30935 and ATM9525818 from the National Science Foundation. 


\section{BERKEY ET AL.: MESOSPHERIC DYNAMICS FROM IDI}

\section{References}

Adams, G.W., D.P. Edwards, and J.W. Brosnahan, The imaging Doppler inteferometer: Data Analysis, Radio Sci., 20, 14811492, 1985.

Adams, G. W., J. W. Brosnahan, D. C. Walden, and S. F. Nerney, Mesospheric observations using a $2.66 \mathrm{MHz}$ radar as an imaging Doppler interferometer: description and first results, J. Geophys. Res., 91, 1671-1683, 1986.

Brosnahan, J.W. and G.W. Adams, The MAPSTAR imaging Doppler interferometer (IDI) radar description and first results, J. Atmos. Terr. Phys., 55, 203-228, 1993.

Charles, K., and G.O.L. Jones, Mesospheric mean winds and tides observed by the Imaging Doppler Interferometer (IDI) at Halley, Antarctica, J. Atmos. Terr. Phys., 61, 351-362, 1999.

East, S.A., N.P. Meredith, M.J. Harris, D. Rees, V.B. Wickwar, I.K. Monson, and H.G.T.I. Muller, First summer results on winds in the upper mesosphere derived from the 843-nm hydroxyl emissions measured from the Bear Lake Observatory, Utah, J. Atmos. Terr. Phys., 57, 9, 995-1008, 1995.

Espy, P.J., J. Stegman and G. Witt, Interannual variations of the quasi-16-day oscillation in the polar summer mesospheric temperature, J. Geophys. Res., 102(D2), 1983-1990, 1997.

Grubb, R. N., The NOAA SEL HF radar system (ionospheric sounder), NOAA Tech. Memo. ERL SEL-55, Space Environ. Lab., Boulder, CO, 1979.

Harris, T.J., A long-term study of the quasi-two-day wave in the middle atmosphere, J. Atmos. Terr. Phys., 56(5), 569-579, 1994.

Jones, G. O. L. and Jarvis, M. J., Springtime reduction in MF mesospheric echo occurrence, Geophys. Res. Lett., 22, 21232126,1995

Jones, G.O.L., K. Charles, and M.J. Jarvis, First mesospheric observations using an imaging Doppler interferometer adaptation of the dynasonde at Halley, Antarctica, Radio Sci., 32(6), 2109-2122, 1997.

Luo, Y., A.H. Manson, C.E. Meek, C.K. Meyer and J.M. Forbes, The quasi 16-day oscillations in the mesosphere and lower ther- mosphere at Saskatoon (52N, 107W), 1980-1996, J. Geophys. Res., 105, 2125-2138, 2000.

Pendelton, W.R., Jr., M.J. Taylor, and L.C. Gardner, Terdiurnal oscillations in $\mathrm{OH}$ Meinel rotational temperatures for fall conditions at northern mid-latitude sites, Geophys. Res. Lett., 27, 1799-1802, 2000.

Roper, R.G., On the reality of upper mesospheric/lower themospheric turbulent "eddies", Radio Sci., 33(1), 67-82, 1998.

Smith, A.K., Structure of the terdiurnal tide at $95 \mathrm{~km}$, Geophys. Res. Lett., 27, 177-180, 2000.

Taylor, M.J., W.R. Pendelton, Jr., C.S. Gardner and R.J. States, Comparison of terdirunal tidal oscillations in mesospheric $\mathrm{OH}$ rotational temperature and $\mathrm{Na}$ lidar temperature measurements at mid-latitudes for fall/spring conditions, Earth, Planets and Space, 51, 877-885, 1999.

Turek, R.S., K.L. Miller, R.G. Roper and J.W. Brosnahan, Mesospheric wind studies during AIDA Act 89: morphology and comparison of various techniques, J. Atmos. Terr. Phys., 57, 1321-1343, 1995.

Turek, R.S., R.G. Roper and J.W. Brosnahan, Further comparisons of simultaneously measured imaging Doppler interferometry and spaced antenna winds, J. Atmos. Terr. Phys., 60, 337-347, 1998.

Wright, J. W., Ionosonde Antennas, in Ionosonde Network Advisory Group (INAG) Bulletin No. 62, P.J. Wilkinson, Editor, January 1998.

F.T. Berkey and Chad S. Fish, Space Dynamics Laboratory, Utah State University, Logan, UT 84322-4145. (email: ftb@cc.usu.edu or chad.fish@usu.edu)

G.O.L. Jones, British Antarctic Survey, Natural Environ-ment Research Council, Madingley Road, Cambridge, CB3 0ET England. (email: o.jones@bas.ac.uk)

(Received June 8, 2000; revised September 13, 2000; accepted October 2, 2000.) 